\title{
Avaliação do Nível de Conhecimento dos Alunos do Ensino Médio da cidade de João Pessoa com Deficiência Visual sobre as Grafias Química e Matemática Braille
}

\author{
João Batista Moura de Resende Filho* \\ Nathália Kellyne Silva Marinho Falcão** \\ Alessandra Marcone Tavares Alves de Figueirêdo*** \\ Maria Fernanda Henrique Odebrecht ${ }^{* * *}$
}

Resumo

O Sistema Braille é de grande importância na educação do aluno com deficiência visual, pois é através dele que o aluno entra em contato com o conhecimento escrito, sistemático e organizado. Este aluno precisa conhecer os símbolos e as normas de uso destes, para poder escrever, ler e compreender os conteúdos. O conhecimento das Grafias Química e Matemática Braille é importante para que os alunos possam compreender os textos dessas áreas. O objetivo deste trabalho foi avaliar o nível de conhecimento dos alunos com deficiência visual matriculados no Ensino Médio na cidade de João Pessoa, no que tange a essas grafias. Os alunos apresentaram um conhecimento relativamente bom nos símbolos e nas normas da Grafia Matemática Braille, apresentando, na maioria dos casos, dificuldades em reconhecer símbolos pouco usuais. As principais dificuldades dos alunos estavam relacionadas à Grafia Química Braille, pois eles desconheciam grande parte dos símbolos e normas, apresentando um baixo nível de conhecimento.

Palavras-chave: Grafia química braille; Grafia matemática braille; Deficiência visual.

\footnotetext{
* Instituto Federal de Educação, Ciência e Tecnologia da Paraíba, Doutorando em Química Inorgânica pela Universidade Federal da Paraíba (UFPB). Joao Pessoa, Paraíba.

** Instituto Federal de Educação, Ciência e Tecnologia da Paraíba, Joao Pessoa, Paraíba.

*** Instituto Federal de Educação, Ciência e Tecnologia da Paraíba, Doutora em Química pela Universidade Federal da Paraíba (UFPB). Joao Pessoa, Paraíba.

**** Instituto Federal de Educação, Ciência e Tecnologia da Paraíba, Graduanda em Licenciatura em Química pelo Instituto Federal de Educação, Ciência e Tecnologia da Paraíba (IFPB). Joao Pessoa, Paraíba.
} 


\title{
Evaluation of the Knowledge Level of High School Students in the João Pessoa City with Visual Impairment About Unified Chemistry and Mathematics Braille Code
}

\begin{abstract}
The Braille Code is very important in the educational process of students with visual impairment, because this writing system allows which the students know the systematic and organized writing knowledge. These students need to know the symbols and the use's standards of them, so they can write, read and understand the contents. The Unified Chemistry and Mathematics Braille Code are fundamentally important for these students to understand the texts about these themes. This study aimed to evaluation of the knowledge level of High School students with visual impairment in the João Pessoa city about Unified Chemistry and Mathematics Braille Code. The students showed a relatively good knowledge of symbols and rules of the Unified Mathematics Braille Code, presenting, in the most cases, difficulties in recognizing unusual symbols. The student's main difficulties were related to Unified Chemistry Braille Code, because they did not know many symbols and writing rules, presenting a low knowledge level.
\end{abstract}

Keywords: Unified chemistry; Mathematics braille code; Visual impairment.

\section{Introdução}

O braille é um sistema de escrita em relevo, tendo como base um conjunto matricial de seis pontos, organizados em três linhas e duas colunas, totalizando 63 símbolos diferentes numa única cela braille, que incluem o alfabeto, simbologias da Matemática e da Química, notação musical, entre outros. Esse sistema de escrita foi criado pelo francês Louis Braille (de onde se originou sua atual nomenclatura) em 1825 e, desde então, poucas modificações foram feitas, permanecendo a mesma estrutura básica até os dias atuais (CERQUEIRA, 2009).

Lemos e Cerqueira (1996) destacam que o Sistema Braille é considerado o método de escrita mais completo, seguro e eficiente, possibilitando, portanto, o acesso das pessoas com deficiência visual à 
instrução, à cultura e à educação, o que, por sua vez, permite a inclusão dessas pessoas na sociedade. Lemos et al. (1999) afirma que o braille permite que os caminhos do conhecimento literário, acadêmico, científico e musical sejam acessíveis às pessoas com deficiência visual, permitindo-lhes terem acesso às mais diversas ideias e, por conseguinte, de atuarem como cidadãos críticos e ativos na sociedade em que vivem.

Considerando a importância do braille para as pessoas com deficiência visual, ele é organizado em diversas grafias e documentos, no intuito de uniformizar e facilitar o trabalho com esse sistema. As Grafias Braille são instrumentos norteadores voltados não apenas para os usuários do Sistema Braille, mas também para professores, transcritores, revisores, entre outros profissionais (BRASIL, 2006b). No Brasil, os principais documentos são: Grafia Braille da Língua Portuguesa (GBLP), Grafia Matemática Braille (GMB) ou Código Matemático Unificado (CMU), Grafia Química Braille (GQB), Musicografia, Grafia Braille para Informática (GBI), Estenografia Braille e Normas Técnicas para a Produção de Textos em Braille.

$\mathrm{Na}$ versão do Sistema editada em 1837, Louis Braille propôs a aplicação do braille à Matemática, porém, este conjunto de símbolos nem sempre foi adotado nos países que vieram a utilizar o Sistema Braille, o que, por sua vez, suscitou em diferenças regionais e locais consideravelmente acentuadas. No Brasil, a Comissão Brasileira do Braille (CBB) adotou o Código Matemático Unificado para a Língua Castelhana, com algumas adaptações necessárias à realidade brasileira, construindo o Código Matemático Unificado para a Língua Portuguesa (BRASIL, 2006a).

Em relação à Ciência Química, buscando desenvolver uma Grafia Braille que atendesse às necessidades advindas do rápido desenvolvimento da ciência e da tecnologia no século XX, o Ministério da Educação junto com a CBB, criaram, em 2000, um Grupo de Trabalho cujo resultado foi à contemplação da Grafia Química Braille para o uso no Brasil. O objetivo deste documento era atender as necessidades dos alunos com deficiência visual no tocante à compreensão da Ciência Química, bem como auxiliar professores e/ou profissionais nesse processo (BRASIL, 2007).

A complexidade do currículo e o gradual aumento quantitativo e qualitativo das aprendizagens próprias dos níveis de ensino (da Educação Básica ao Ensino Médio) exigem linguagens e recursos específicos nas áreas de conhecimento contempladas, a exemplo de Física, Química e Matemática (RAPOSO; CARVALHO, 2005). Para que o deficiente visual possa se apropriar do conhecimento dessas disciplinas é necessário que ele consiga compreender seus códigos e representações. 
Desta forma, percebe-se a importância do conhecimento destas Grafias Braille para que o aluno com deficiência visual possa aprender e compreender os conteúdos referentes às respectivas disciplinas. $\mathrm{O}$ acesso a modelos verbais escritos relacionados a áreas de conhecimento das Ciências Exatas (Química, Física e Matemática) está, dentre outros fatores, fundamentado no conhecimento da simbologia específica utilizada nesses textos.

Posto isso, o presente trabalho busca avaliar o nível de conhecimento dos alunos deficientes visuais inseridos nas escolas da cidade de João Pessoa (PB) acerca das Grafias Química e Matemática Braille.

\section{Metodologia}

Para realizar o presente estudo, optou-se por trabalhar com o universo dos alunos com deficiência visual matriculados no Ensino Médio em instituições regulares de ensino, situadas no município de João Pessoa. A lista de instituições de ensino cadastradas no Ministério da Educação (MEC) encontra-se disponível no site do MEC (http://www.dataescolabrasil.inep. gov.br/dataEscolaBrasil/), totalizando 91 escolas, sendo 46 públicas e 45 privadas no determinado município. A Tabela 1 apresenta as características das instituições de ensino e da turma que apresentavam alunos deficientes visuais (DVs) regularmente matriculados.

Tabela 1 - Caracterização das instituições de ensino e das turmas.

\begin{tabular}{ccccc}
\hline Nome & Rede de ensino & Séries* $^{*}$ & $\begin{array}{c}\text { Número de } \\
\text { alunos DVs }\end{array}$ & $\begin{array}{c}\text { Número total } \\
\text { de alunos }\end{array}$ \\
\hline Instituição 1 & Federal $^{* *}$ & $1^{\circ}$ ano & 2 & 40 \\
Instituição 2 & Estadual & $1^{\circ}$ ano & 2 & 30 \\
Instituição 3 & Estadual & $2^{\circ}$ ano & 2 & 39 \\
Instituição 4 & Estadual & $1^{\circ}$ ano & 1 & 35 \\
& & $3^{\circ}$ ano & 4 & 35 \\
Instituição 5 & Estadual & $1^{\circ}$ ano & 2 & 35 \\
\hline
\end{tabular}

* Séries em que haviam alunos DVs matriculados.

** Ensino Médio Integrado ao Técnico de Música. 
No intuito de fornecer maiores dados para a caracterização do público alvo desta pesquisa, foi realizada uma entrevista com os alunos DVs, separadamente. Tal entrevista fornece dados para a construção do quadro educacional, social e familiar no qual o aluno está inserido, permitindo uma análise mais criteriosa dos resultados da pesquisa, especialmente àqueles vinculados às dificuldades no processo de ensino-aprendizagem.

Após a realização da entrevista, foram aplicados dois questionários, um referente à Grafia Matemática Braille e outro à Grafia Química Braille. Estes questionários tinham por objetivo identificar o nível de conhecimento dos alunos DVs referente às respectivas grafias.

\section{Resultados e discussões}

\section{Entrevista}

Todos os alunos entrevistados estão inseridos na rede regular de ensino público da cidade de João Pessoa, distribuídos nas três séries do Ensino Médio $\left(1^{\circ}, 2^{\circ}\right.$ e $3^{\circ}$ anos), conforme está apresentado na Tabela 1. A entrevista abordou os seguintes tópicos: a deficiência visual, o desenvolvimento do processo de ensino-aprendizagem dos discentes até o corrente ano, a relação aluno/família, aluno/professor e aluno/colegas.

No que tange à deficiência visual, de acordo com o laudo médico dos alunos, $54 \%$ foram diagnosticados como tendo cegueira, enquanto que os outros $46 \%$ foram diagnosticados como tendo visão subnormal (baixa visão). Quando questionados sobre a causa da deficiência, obtivemos respostas dessemelhantes para todos os casos, e apenas um aluno DV não soube descrever a causa da deficiência. As causas mencionadas pelos alunos foram: degeneração da retina, parto demorado, síndrome de Marfan, glaucoma, deslocamento da retina, má formação da retina, rubéola, catarata, toxoplasmose e miopia aguda.

Vale a pena frisar que, do ponto de vista pedagógico, é considerado cego o aluno que necessita de instrução em braille para a realização das suas atividades educacionais, enquanto que o aluno com baixa visão é aquele que pode ler textos impressos em fontes ampliadas ou utiliza-se de recursos ópticos, tais como lentes de aumento, lupas etc. (REIS et al., 2010). Por conseguinte, os alunos que fizeram parte desta pesquisa podem ser considerados como cegos, tendo em vista que 100\% deles utilizam o Sistema Braille nas suas atividades escolares. 
Quando questionados acerca do seu processo educacional, obtivemos algumas respostas que nos atentam à necessidade de melhorar o processo de inclusão escolar. Ao avaliarem o processo educacional pelo qual eles passaram, observamos que poucos alunos consideraram-no satisfatório, tendo a maioria classificado-o como "regular" (Figura 1).

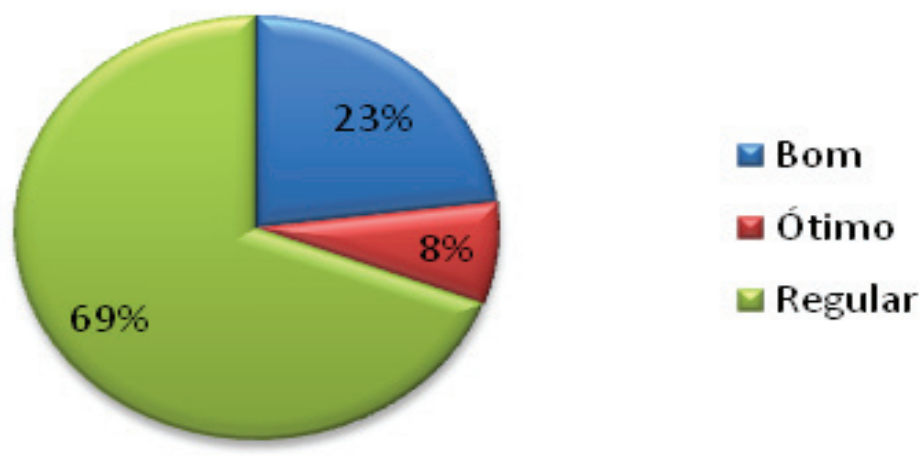

Figura 1 - Classificação do processo educacional segundo os alunos DVs.

No intuito de verificar o porquê dessa classificação, foi questionado aos alunos sobre quais eram as principais dificuldades que eles tiveram durante o processo educacional. Dentre as dificuldades, os alunos mencionaram, basicamente, dois aspectos: (a) metodologia do professor e (b) falta de materiais didáticos adaptados a sua deficiência.

De acordo com Souza (2010) a maioria dos professores se sente despreparada frente à presença ou à possibilidade de atenderem alunos com deficiência visual, e isto é refletido na metodologia aplicada em sala de aula. As metodologias consistem em aulas meramente expositivas e predominantemente visuais, utilizando-se, na maioria dos casos, apenas do livro didático, do quadro e do giz/pincel como recursos didáticos. Apesar da importância desses recursos para os alunos normovisuais, sua eficiência didática para o aluno DV é consideravelmente baixa quando usados isoladamente, sem o auxílio de recursos táteis que os auxiliem na compreensão da retórica do professor. Imagens, esquemas, gráficos, tabelas etc. geralmente não são descritos para o aluno DV durante as aulas, fazendo com que ele se sinta "perdido" diante dos acontecimentos em sala de aula. 
Segundo os alunos entrevistados, uma metodologia de ensino que aborde outras percepções, além da visual, vinculada à utilização de materiais didáticos seria fundamental para uma aprendizagem mais efetiva. Se o aluno DV não tiver acesso a representações ou descrições de gráficos e esquemas utilizados para indicar variações que acontecem nos processos de estudo, ele passa a se sentir excluído do processo de ensino-aprendizagem pela falta de acessibilidade à informação.

A utilização de representações para explicar conceitos e fenômenos é comumente utilizada, porém, estes instrumentos podem tornar-se um obstáculo para o aluno DV, pois eles são majoritariamente visuais. Podemos perceber isso claramente nas disciplinas das denominadas Ciências Exatas. Enquanto que o aluno normovisual pode compreender, por exemplo, o comportamento de uma função afim, quadrática ou exponencial escutando as explicações do professor e acompanhando, visualmente, a construção da curva em um plano cartesiano no quadro ou no seu livro didático, o aluno DV precisa entendê-lo apenas com a retórica do professor, ou seja, apenas com o que escuta. Além disso, nos estudos em horário extracurricular, eles precisam conhecer a simbologia usada na Matemática, assim como as suas regras de uso que estão compiladas no Código Matemático Unificado, para poder ter acesso ao material escrito.

Apesar da existência de recursos didáticos que facilitariam a compreensão desses conteúdos, tais como o geoplano, o multiplano, entre outros, nenhum dos professores utilizam esse material, nem as respectivas instituições de ensino os possuem para uso.

A dificuldade que esses alunos apresentam nessas disciplinas é notória, logo, a motivação para o estudo daquelas fica comprometida. Podemos verificar que a grande maioria dos alunos DVs $(54 \%)$ citou a disciplina de Português como sendo aquela em que eles possuíam uma maior facilidade de aprendizado e compreensão (Figura 2). Eles justificaram sua escolha pelo ensino desta disciplina ser mais oral (e, consequentemente, menos visual) do que as demais, o que facilita o aprendizado dos discentes, já que eles só dispõem, basicamente, da retórica do professor. 


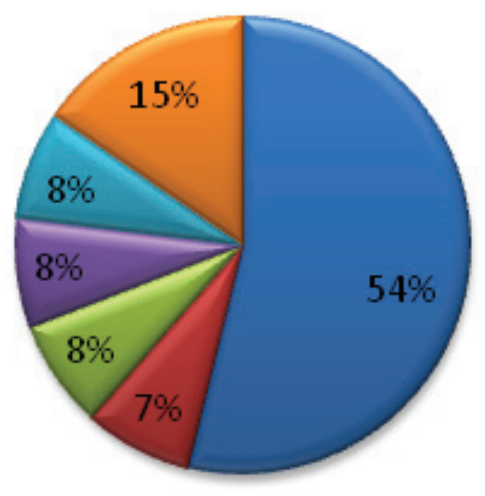

Dortuguês

Matemática

$\square$ História

Teoria Musical

$\square$ Inglês

$\square$ Nenhuma

Figura 2 - Disciplinas que os alunos DVs apresentavam maior facilidade no aprendizado.

As disciplinas das Ciências Exatas são apontadas como as mais difíceis e complicadas. Isto se dá devido ao grande vínculo visual relacionado a essas disciplinas, considerando a utilização de gráficos, desenhos, modelos e experimentos fundamentais para a compreensão de um dado conteúdo (RAPOSO; MÓL, 2010). Considerando esse quadro, foi solicitado aos alunos que eles atribuíssem um nível de dificuldade para o aprendizado das disciplinas Química, Matemática e Física, segundo uma escala hedônica de 10 categorias (Figura 3).

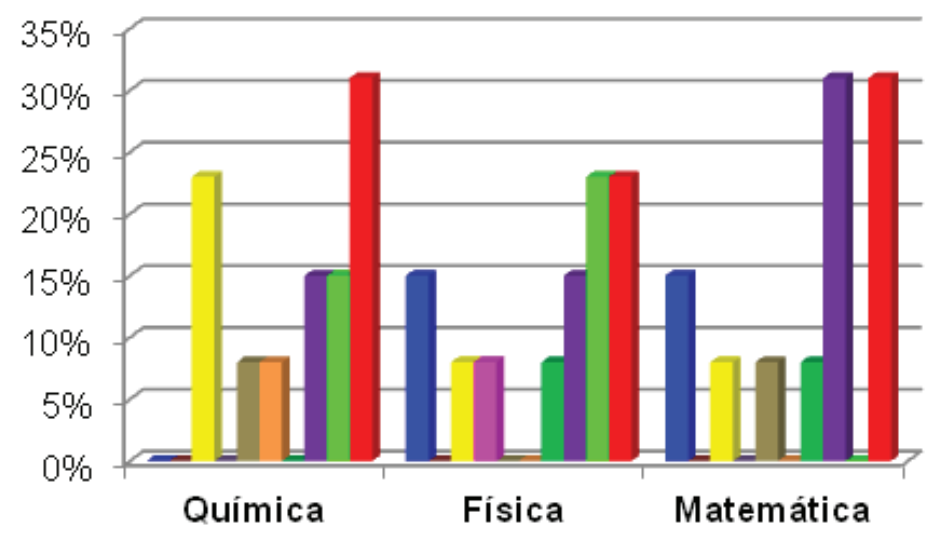

- Nivel 1

- Nivel 2

Nivel 3

- Nivel 4

- Nivel 5

- Nivel 6

- Nivel 7

- Nivel 8

- Nivel 9

- Nivel 10

Figura 3 - Níveis de dificuldade atribuídos às disciplinas Química, Física e Matemática. 
Os discentes que afirmaram ter dificuldade entre os níveis 7 e 10 justificaram-na, novamente, pela falta de materiais didáticos e pela metodologia utilizada pelos professores não ser adequada as suas necessidades, além de mencionarem a falta de capacitação destes últimos, tendo em vista que nenhum deles possuíam conhecimento do código braille e muitos não sabiam como trabalhar determinado conteúdo com o aluno DV.

A utilização de recursos didáticos adaptados à deficiência visual busca apoiar tanto os alunos quanto os professores no processo de ensinoaprendizagem. Raposo e Mól (2010) propõem que quando a utilização da grafia tátil não for suficiente para a representação e apreensão de conceitos científicos, além do uso da Grafia Braille, as ideias devem se materializar em modelos, maquetes, gráficos em relevo e experimentos adaptados cujas observações e apropriação baseiam-se no tato, audição, olfato e gustação.

Em última instância, os alunos foram interrogados acerca da utilização e da importância do Sistema Braille para a realização de atividades cotidianas, escolares ou não. Nós percebemos uma considerável relevância dada por esses alunos à escrita, o que pode ser identificado em algumas das passagens abaixo, citadas pelos alunos:

- "É um método que o deficiente visual encontra para ser independente na leitura e na escrita." (Aluno 3)

- "É minha única forma de estudar, escrever e me expressar. O braille pra mim é tudo!" (Aluno 7)

- "O braille pra mim é tudo, porque utilizo-o na minha vida. O braille são pontos que constrói pontes." (Aluno 12)

Segundo Bertalli (2010), o Sistema Braille interage com o deficiente visual através da conversa em português, permitindo o acesso à leitura e à escrita, desmistificando a ideia de que o aprender depende apenas do ver.

No que se refere à relação aluno/família e aluno/colegas, a grande maioria dos alunos responderam possuírem uma boa relação com a família e os amigos, recebendo o apoio necessário por parte de ambos. Apenas $8 \%$ dos alunos, relataram uma relação ruim, pois algumas das pessoas envolvidas não aceitavam a sua deficiência como uma característica humana. Por conseguinte, os resultados oriundos dos questionários referentes à $\mathrm{GMQ}$ e à $\mathrm{GBQ}$ refletem, basicamente, as dificuldades no processo de ensino- 
aprendizagem e no desenvolvimento escolar, apresentando pouca influência (negativa) do ambiente familiar e social (amigos e colegas).

\section{Conhecimento das grafias química e matemática braille}

Os questionários foram construídos com base em todos os conteúdos do Ensino Médio descritos na Grafia Matemática Braille e na Grafia Química Braille, separados por ano (série) de ensino. O primeiro questionário (referente à GMB) consistia em um roteiro de 25 tópicos norteadores, na qual as respostas dos alunos DVs foram classificadas em três níveis: conhecimento elevado (CE), parcial (CP) e baixo (CB).

Vale a pena destacar que uma parte significativa dos alunos utilizavam símbolos diferentes daqueles descritos nas grafias, sem mencionar que desconheciam as normas de uso desses símbolos. Numa das questões, por exemplo, apenas dois alunos DVs utilizavam corretamente os parênteses auxiliares, sinal exclusivo do braille utilizado em expressões matemáticas para unificar termos sem sinais unificadores. Este sinal é de suma importância, pois ele evita inúmeras confusões durante a leitura. O desconhecimento deste sinal (assim como outros) por alunos que se encontram no Ensino Médio (alguns já no fim desta etapa) é um ponto consideravelmente preocupante, pois ele não apenas dificulta a compreensão do conteúdo como inviabiliza o processo de ensino-aprendizagem. Como o aluno DV poderá ter acesso ao conhecimento se ele desconhece aquela simbologia? Como ele poderá escrevê-la ou lê-la? Como poderá compreender o modelo matemático escrito utilizado pelo professor ou presente em um livro didático, se ele desconhece os caracteres que constituem as expressões matemáticas?

Segundo Raposo e Carvalho (2005), a utilização adequada das Grafias viabiliza a permanência na escola com perspectivas de sucesso, possibilita a construção de expectativas positivas em relação à vida profissional e social da pessoa com deficiência visual.

A Figura 4 mostra o nível de conhecimento dos DVs de acordo com os capítulos da GMB, organizados de acordo com os conteúdos e símbolos utilizados em cada série. 

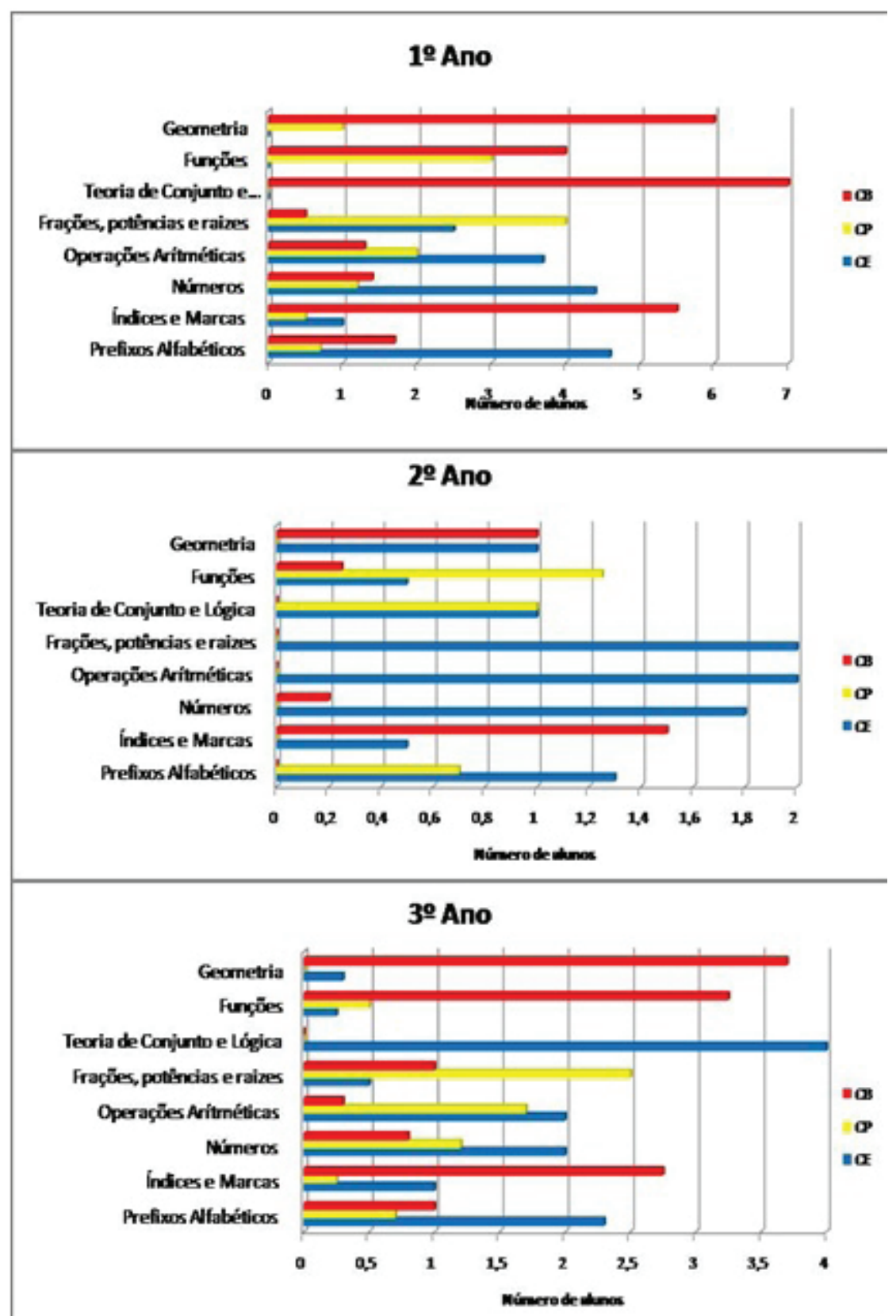

Figura 4 - Respostas agrupadas por níveis de conhecimento dos alunos com deficiência visual, organizadas por conteúdos da GMB. 
Podemos perceber que os alunos DVs do $1^{\circ}$ ano apresentaram um baixo conhecimento das simbologias utilizadas na GMB. Em contrapartida, os alunos do $2^{\circ}$ e do $3^{\circ}$ ano apresentaram um maior conhecimento dessas simbologias, assim como as regras de uso dessas. Esse quadro pode encontrar explicação no fato de que, à medida que eles vão caminhando no processo educacional, esses símbolos se tornam cada vez mais frequentes, necessitando, portanto, serem constantemente escritos e repetidos, o que, por sua vez, ajuda no aprendizado das respectivas simbologias. Já os símbolos e regras que os alunos do $2^{\circ}$ e $3^{\circ}$ ano desconheciam, tais como aqueles referentes ao capítulo de Geometria e de Índices e Marcas, não foram usados até o presente momento e, quando foram, eles utilizaram uma notação que não correspondia àquela presente na GMB. Esse último caso também foi verificado nos conteúdos do capítulo de Funções com os alunos DVs do $3^{\circ}$ ano.

Vale a pena destacar que as dificuldades encontradas no $1^{\circ}$ ano não podem ser desconsideradas. O desconhecimento das simbologias e suas regras de uso podem dificultar e atrasar o processo educacional desses alunos, tornando o aprendizado difícil e até mesmo inviável. Sem o conhecimento desses símbolos, o aluno DV não poderá ler conscientemente o desenvolvimento de um raciocínio matemático expresso em um modelo matemático escrito. Analogamente, é como se tentássemos ler um texto em hieróglifos antigos, sem ter o mínimo de conhecimento sobre o que esses símbolos significam.

Considerando o gráfico da Figura 4, agrupamos as respostas dos alunos DVs por série e, em seguida, separamo-las em respostas do tipo CB, $\mathrm{CP}$ ou $\mathrm{CE}$, nos fornecendo uma visão geral do nível de conhecimento desses alunos referente à grafia, conforme mostra a Figura 5 . Desse quadro, o mais preocupante é o do $1^{\circ}$ ano, onde apenas $28,9 \%$ das respostas apresentaram um CE, enquanto $48,9 \%$ das respostas foram consideradas como CB. 

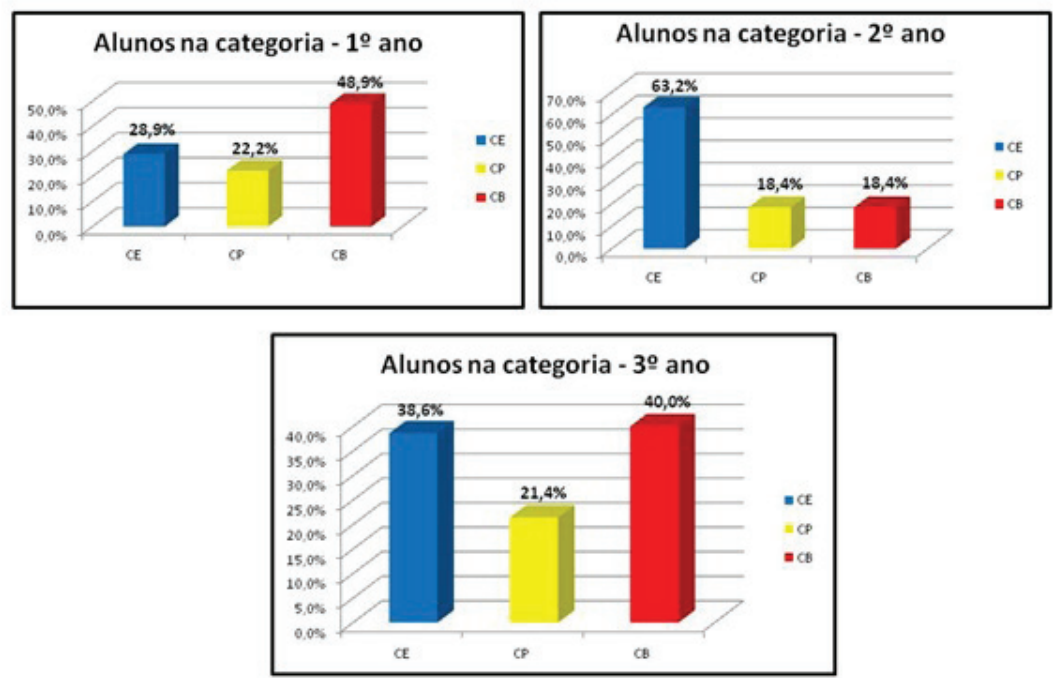

Figura 5 - Resultado global do nível de conhecimento das respostas dos alunos DVs referentes à GMB.

O segundo questionário (referente à GQB) consistia em um roteiro de 19 tópicos norteadores. A maioria dos discentes não apresentou um bom nível de conhecimento da GQB. Considerando a entrevista feita com os alunos DVs, este resultado já era esperado, visto que a disciplina Química foi apontada pela maioria dos discentes como sendo abstrata e uma das mais difíceis de aprender. A Figura 6 mostra o nível de conhecimento dos alunos DVs em concordância com os capítulos da GQB, organizados de acordo com os conteúdos e símbolos trabalhados em cada série. 




Figura 6 - Respostas agrupadas por níveis de conhecimento dos alunos com deficiência visual, organizadas por conteúdos da GQB. 
O desconhecimento dos símbolos pertencentes a essa grafia era consideravelmente grande. Eles não sabiam como representar símbolos simples e essenciais para a compreensão de modelos escritos, tais como o símbolo do elemento químico, fórmulas moleculares, equações químicas, entre outros. Vários alunos (69\%) disseram que representavam os elementos químicos escrevendo todo o seu nome, tendo em vista que não sabiam qual o símbolo químico correspondente ao elemento. Já na escrita de fórmulas moleculares, os alunos não sabiam como escrever corretamente. $\mathrm{Na}$ escrita da formular molecular da água $(\mathrm{H} 2 \mathrm{O})$, por exemplo, eles escreviam erroneamente "H dois O" ou "H2O". Em conformidade com a GQB, deve-se escrever o índice utilizando-se o símbolo equivalente na série de transladação ( $5^{\mathrm{a}}$ série da Ordem Braille) sem o uso do sinal de número. Apenas alguns dos entrevistados responderam corretamente.

Além do uso incorreto da maioria das representações utilizadas na Química, o número de símbolos e regras que esses alunos desconheciam é bastante elevado. Por exemplo, nenhum dos alunos tinha conhecimento da existência do Símbolo Braille Delimitador e do Símbolo de Abreviação de Funções Orgânicas, símbolos estes que servem para evitar confusões e economizar espaço, respectivamente.

À semelhança do que foi feito na GMB, foi agrupado o total de resposta dos discentes representado na Figura 6, separando-as por série e classificando-as como CB, CP ou CE, nos fornecendo uma visão geral do nível de conhecimento desses alunos quanto à GQB, conforme mostra a Figura 7.
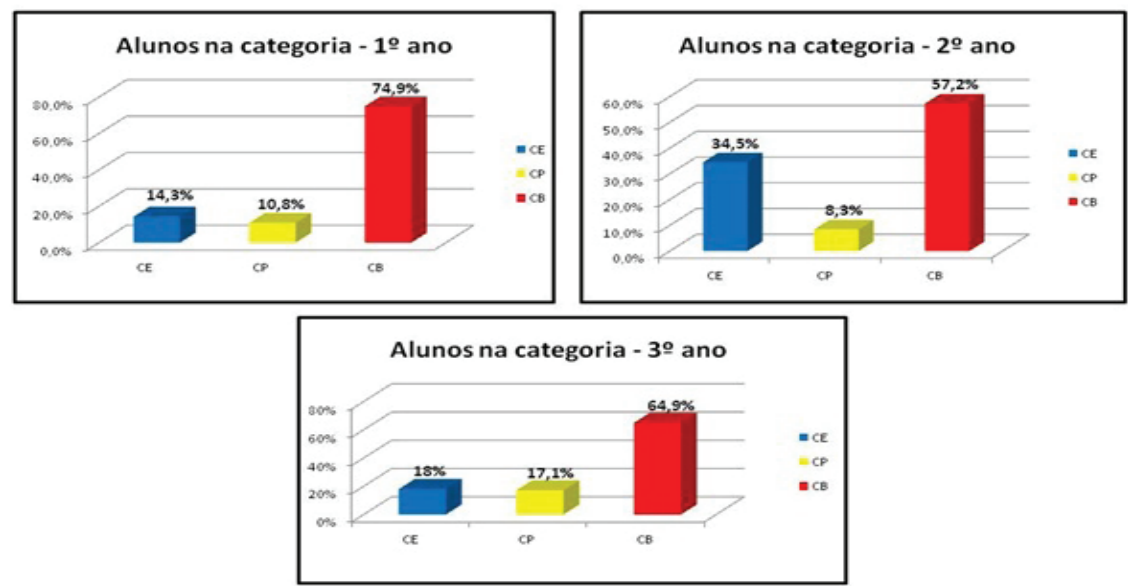

Figura 7 - Resultado global do nível de conhecimento das respostas dos alunos DVs referentes à $\mathrm{GQB}$ 
A Figura 7 nos mostra como o nível de conhecimento dos alunos DVs matriculados no Ensino Médio no que diz respeito à simbologia da Química é baixo: $75 \%, 58 \%$ e $65 \%$ das respostas dos alunos do $1^{\circ}, 2^{\circ}$ e $3^{\circ}$ ano, respectivamente, foram consideradas como CB. Esse pode ser considerado como um dos principais fatores para as dificuldades que os alunos DVs encontram em aprender a disciplina de Química, pois, se eles não entendem o modelo escrito que leem, nem sabem como escrevê-lo corretamente, não há como compreender o conteúdo abordado.

\section{Considerações finais}

O Sistema Braille é, sem dúvida, indispensável na vida dos alunos com deficiência visual. Este sistema possibilita que esses discentes possam escrever e ler, tendo acesso ao conhecimento organizado. A adaptação da metodologia utilizada pelo professor e a utilização de materiais didáticos que visem a facilitar o aprendizado dos mais diversos conteúdos também são de grande relevância. Para tanto, faz-se necessário que o professor seja capacitado para trabalhar com esses alunos. E, nesse processo, ressaltamos a importância de que ele conheça o braille, de modo a facilitar o processo de ensino-aprendizagem dos alunos DVs, familiarizando-os com as simbologias da respectiva Ciência.

O nível de conhecimento dos alunos DVs matriculados no Ensino Médio da cidade de João Pessoa no que concerne ao uso correto dos símbolos compilados nas Grafias Química e Matemática Braille é consideravelmente baixo, principalmente em relação à GQB. Este quadro é preocupante, pois sem o conhecimento da escrita, o acesso ao conhecimento é prejudicado. Além do baixo nível de conhecimento dos alunos, o despreparo dos professores e a falta de materiais didáticos usados em sala de aula só tende a piorar o respectivo quadro.

Algumas ações para reverter esse cenário podem ser tomadas, tais como cursos específicos da GMB e GQB para os alunos DVs; capacitação dos professores no que tange ao Sistema Braille e a metodologias de ensino adequadas às necessidades dos alunos DVs; oficinas para a confecção de materiais didáticos que explorem as mais diversas percepções sensoriais; entre outras.

Os alunos DVs precisam conhecer os símbolos das Ciências Matemática e Química para terem acesso à informação escrita, relacionadas a essas áreas, e para poderem expressar seus conhecimentos. A partir deste ponto, é que eles poderão construir e reconstruir pensamentos e ideias 
coerentes e comunicar-se com o mundo que o cerca, efetivando-se, portanto, o processo de ensino-aprendizagem.

\section{Referências}

BRASIL. Código Matemática Unificado para a Língua Portuguesa - CMU. Brasília: MEC, SEESP, 2006a.

2006b.

Grafia Braille para a Língua Portuguesa. Brasília: MEC, SEESP, 2007

Grafia Química Braille para Uso no Brasil. Brasília: MEC, SEESP,

Ministério da Educação. Disponível em: <http://www. dataescolabrasil.inep.gov.br/dataEscolaBrasil/>. Acesso em: 10 out. 2011.

CERQUEIRA, J. B. O Legado de Louis Braille. Revista Benjamin Constant, Rio de Janeiro, n. esp., 2009.

CERQUEIRA, M. G. C. Proposta de formação continuada para professores, visando a inclusão do aluno deficiente visual/cego nas escolas regulares. 2002. Dissertação (Mestrado em Educação) Universidade Estadual de Feira de Santana, Feira de Santana (BA), 2002.

LEMOS, E. R.; CERQUEIRA, J. B.; VENTURINI, J. L.; ROSSI, T. F. O. Louis Braille: sua vida e seu sistema. 2. ed. São Paulo: FDNC, 1999.

LEMOS, E. R.; CERQUEIRA, J. B. O sistema Braille no Brasil. Revista Benjamin Constant, Rio de Janeiro, n. 2, 1996.

RAPOSO, P. N.; CARVALHO, E. N. S. Inclusão de alunos com deficiência visual. In: SORRI-BRASIL (Org.). Ensaios Pedagógicos: construindo escolas inclusivas. 1. ed. Brasília: MEC, SEESP, 2005. p. 140-144.

RAPOSO, N. R.; MÓL, G. S. A Diversidade para aprender conceitos científicos. In: SANTOS, W. L. P.; MALDANER, O. A. (Orgs.). Ensino de Química em foco. ljuí: Unijuí, 2010. p. 296-302.

REIS, M. X.; EUFRASIO, D. A.; BAZON, F. V. M. A formação do professor para o ensino superior: prática docente com alunos com deficiência visual. Educação em Revista, Belo Horizonte, v. 26, n. 1, p. 111-13, 2010. 
SOUZA, O. S. H. Acessibilidade: problematizando a integração do DV no contexto escolar. Disponível em: <http://intervox.nce.ufrj.br/ abedev/TextoOlga.doc>. Acesso em: 04 jun. 2012.

\section{Correspondência}

Alessandra Marcone Tavares Alves de Figueirêdo - Instituto Federal de Educação, Ciência e Tecnologia da Paraíba, Coordenação do Curso de Licenciatura Em Química, Sede.

Av.: $1^{\circ}$ de Maio, 720, Jaguaribe, CEP: 58015-430 - Joao Pessoa, Paraíba - Brasil.

E-mail: jb.petquimica.cefetpb@hotmail.com - nathalia_kellyne15@hotmail.com - nathalia_ kellyne15@hotmail.com - fernanda_odebrecht@hotmail.com

Recebido em 25 de outubro de 2012

Aprovado em 04 de fevereiro de 2013 